\title{
CREATIVE PROBLEM-FINDING: A SHIFT IN FOCUS FOR CREATIVE TOOLS
}

\author{
Ellen DE VOS ${ }^{1,2}$, Bas BACCARNE ${ }^{2}$ and Marina EMMANOUIL ${ }^{1}$ \\ ${ }^{1}$ Research Group design.nexus, Department of Industrial Systems Engineering and Product \\ Design, Ghent University \\ ${ }^{2}$ Research Group imec-mict-UGent, Department of Industrial Systems Engineering and \\ Product Design, Ghent University, Belgium
}

\begin{abstract}
Identifying and forming problems is an important first step in the problem-solving process in the design field (and beyond). A valuable definition of creative problem-solving includes, on the one hand, the production of original, high quality, appropriate solutions, and, on the other hand, novel, complex, illdefined or poorly structured problems that challenge these results [1]. Researchers, namely Wakefield (1985) argued that finding a problem is in fact more important than solving it, because it expands the potential to discover new possibilities [2]. However, the process of finding and identifying relevant problems remains fuzzy. An important reason why creative problem-solving fails, is related to the problems' nature [3]. With this research we aim to offer a better understanding on how design problems are defined, by means of a tool, a graphic canvas. The purpose of most creative techniques is solving problems or generating ideas in the development of new services or products. Considering the added value of practice and coaching of problem-finding abilities in industry and education, and also the intrinsic goal of creative tools to develop the capacity of people's innate potential, a method for problem description was developed. In order to validate the tool, we implemented it in the search process for master's thesis topics. By sharing our insights on the canvas/template creation and user feedback in the context of design education, we support the increasing attention that is given to the need of exploring problem-finding with an essential shift in creative problem-solving tools.
\end{abstract}

Keywords: Design education, creative problem-solving, problem-finding, creativity

\section{INTRODUCTION}

Since the 1960's there has been a noticeable interest in the creative problem-solving process, especially in the constructs divergent thinking and problem-solving [4]. Recently, we have noticed a shift in both research and (educational) practice towards the process' initial phase: problem finding. Lee et. al. (2020) define this 'problem-first design process' as follows: 'A design process that emphasizes defining and understanding a presented problem as a starting point, followed by a search for solutions' [5]. We notice an emerging call for designers who are consciously monitoring our environment, trying to spot problems with high urgency. The closer the expected time to start directing these problems, the more impact and value possible solutions might have. Moreover, a common assumption nowadays both in the industrial and academic domain on product design and development, says it is crucial to improve problem-solving skills to reach valuable innovations [6]. However, there is not yet a consensus on the process that evolves when individuals detect, pose or formulate problems [4].

In this paper, we share our insights on both process and outcomes of a tool created to facilitate design students to better develop the problem definition for the topic of their master's thesis. Once they have discovered an issue or a problem, our tool would potentially help to delve into it. A particular point of attention is given to the background of the designer/student: several questions about the designers' motivation, expertise or competence were added to the tool. In this way, the students are stirred to reflect not only on which problem they want to tackle, but also why they should try to solve it. After contributing some background information on this ongoing evolution, the paper continues with the development of the tool and its implementation in our design curriculum. To conclude, we bridge our findings based on interviews with students and recommendations from literature. 


\section{BACKGROUND}

\subsection{Creative design problems' ('wicked') nature}

In their definition of creative problem-solving, Mumford and Gustafson (2007) revealed several characteristics of the problems designer's address: they include a level of novelty and complexity, and are, additionally, ill-defined and poorly structured [1]. Indeed, the opposite of mild, manageable problems has been introduced in 1973 as 'wicked problems' [7]. While wicked problems would have more chance to lead to novelty [8], their nature is an important reason why conventional creative problem-solving fails [3]. One possible reason is that solving one aspect of it, may uncover or stimulate another challenge that potentially remains unsolved. Furthermore, the core issue is probably linked to a combination of dynamic and multidisciplinary causes that hinders to resolve isolated sub-problems oneby-one [9]. Therefore, it is worth examining how to facilitate the exploration of a (wicked) problem, which is both intriguing and potentially problematic.

\subsection{Problem-first design process}

Traditionally, the emphasis of research lies on the product or outcome of creative processes rather than on an understanding of the process by which these creative endeavours happen [10]. Although the effect of problem finding on creativity itself is perhaps not fully recognized [4], researchers have found that when paying more attention to the careful statement of (wicked) problems, the related solutions exceed business-as-usual or uninspired puzzle-solving [9]. Several problem-finding strategies have been identified: exploring the underlying needs; defining a problem space with deliberate boundaries, applying intentionally different points of view on the problem; broaden the inquiry towards the context and the stakeholders of a problem [4]. Although research has confirmed that design problems can evolve even with the realization of solutions throughout a design process, reasonable efforts at the beginning have their significance during the subsequent search for satisfactory solutions [11]. Hence, several tools have been created to assist this important quest.

\subsection{Benchmarks}

While searching for existing creative tools that focus on the initial stage of the design process, different instruments are observed: on the one hand, those who support a divergent thinking approach in freely guiding a stream of consciousness, and, on the other hand, converging medium's structure one's thoughts in the direction of a decision.

The 'Opportunity Mind Map' from Mindshake is based on the work of psychologist Tony Buzan and has specifically been created for implementation in a design-thinking-towards-innovation process [12]. What we appreciate in this divergent thinking-instrument is the non-linear notetaking and its visual approach that aims at stimulating user's motivation. Furthermore, we agree upon the advice given that involving guests in a second or third iteration of the tool would gather new insights on the central subject [12]. From the same Mindshake-toolkit, the convergent Intent Statement clarifies for the user the orientation of the innovation challenge while asking the following questions: What is your intention? What are the opportunities? What is the new value you are creating? New for whom: the company, the city, the country or the world? What is your target group? What are the risks of a possible flop of the project? Users are instructed to use this template as a starting point rather than as a document of which the input is no longer considered editable [12]. We believe that providing such a clear and unambiguous examination can be very beneficial.

Finally, another tool concerns the 'User Innovation Toolkit' that includes a primary phase where reflecting on the features of innovation challenges is required: S.M.A.R.T description. According to De Marez, problems should be described as Specific, Measurable, Achievable, Relevant and Time-bounded entities [13]. This framework is narrowing down the options users still did not define. Although we take other features of (wicked) problems into consideration, this example shows how indicating the key elements of a problem, can be of great value.

\section{TOOL DEVELOPMENT AND IMPLEMENTATION IN DESIGN EDUCATION}

Students in design education usually get a predefined assignment or can choose their own subject within a certain framework based on the learning goals of the specific course. However, if we want to educate the future designers to be able to discover valuable challenges themselves, adequate exercises that stimulate this skill need to be provided. It is by far more difficult to come with an idea for a problem 
from scratch [14]. Surely, this focus on problem-finding should be introduced in a scaffolding way. Similar to many design schools, the students of the Industrial Design Engineering programme at Ghent University are confronted with this challenge for the first time: at the time they start searching for a master's thesis subject in their third year of their bachelor's programme. Although different anchors are given, e.g., the students can contact companies that are familiar with the programme and their teachers provide a list of topics, we stimulate the students to come up with a self-defined proposal.

\subsection{Context}

A coherent group of twenty-six, third year bachelor Industrial Design Engineering students were asked in the context of their course on design methodology to reflect on their master's thesis subject. The final deliverable was a text to explain which valuable challenge they consider tackling and which particular methodology they would apply in order to solve that. At several moments during this first semester course, we familiarized the students with the process of searching a subject (Figure 1). At first, there was an introduction presentation with general facts about how master's topics are collected and categorized under specific learning lines. Prior to that presentation, students had been asked to brainstorm during five minutes on plausible subjects coming from their own interests. Immediately after describing the applicable guidelines, half of the students were given our tool, whereas the other half of the class were told to brainstorm freely. Eventually, time was taken to explain the tool to the entire class group. All students were asked to complete the tool (anew) before the following class, the week after. Finally, we suggested to perform the tool for a final time before they started writing their text.

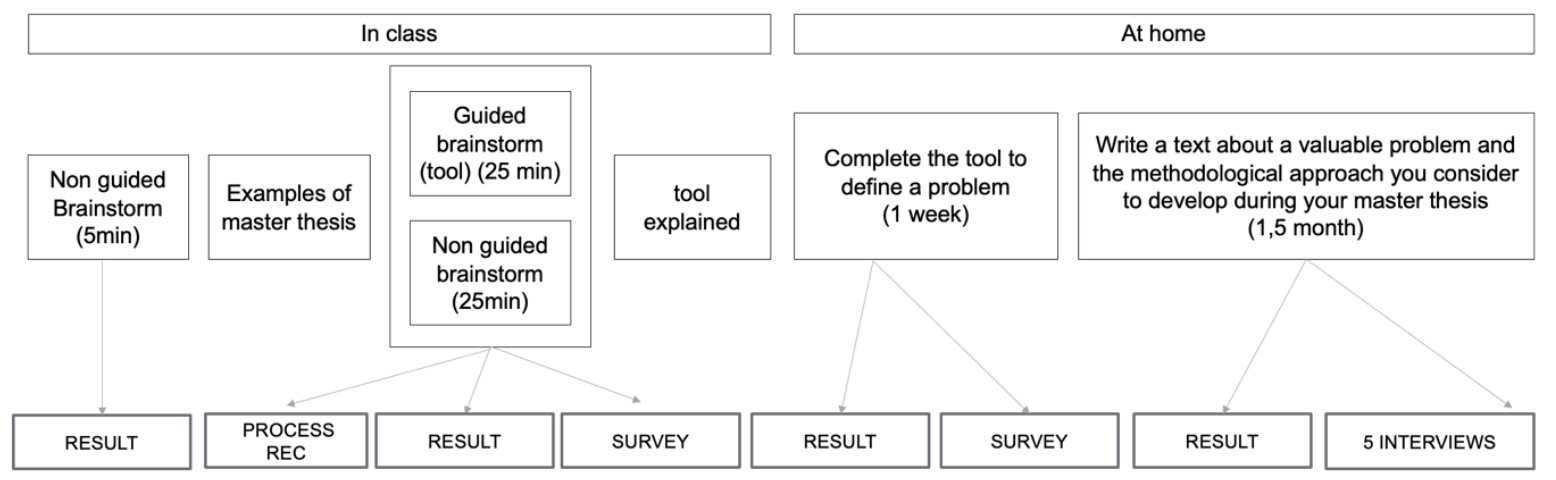

Figure 1. Process of context and feedback gathering

\subsection{Tool development}

Dorst (2006) clarified the dissimilarities between well-structured and ill-structured problems, emphasizing that those dissimilarities can be related to the skills of the problem solver. The designer's interpretation of the problem based on his/her prior knowledge and experience, should be given some attention [15]. Moreover, inspired by the Self-Determination Theory, we encourage values as autonomy, competence and relatedness to, on the one hand, stimulate students' internal and external motivation, and, on the other hand, help to estimate the achievability of their goals [16]. Therefore, on the left area of the graphic canvas, students were asked about their motivation, capabilities and resources.

Our tool aims at helping the students formulating their chosen problem. While Dorst and Cross (2001) defined this as 'alter presented characteristics to align with imposed frames and establishing problem boundaries' [11], this framing should as well stimulate to apply different perspectives and viewpoints to the problem: the personal view, the sectioning in subproblems, the focus on its novelty - the opportunities - and the reflection on its possible disadvantages [1]. Also, an early mention of stakeholders contributes to broaden the topic [4].

In particular, these wicked challenges are usually positioned at the crossings of multiple disciplines, therefor several input fields are provided to reflect on the kind of information needed to solve the challenge and the necessary resources. 'Who can you have a functional debate with about the described problem?' is an example of such an input field.

Also, attention is given to some of these problems' characteristics. As mentioned above, there is at least a minimum of complexity and opportunity for novelty. The problem can initially be ill-defined, which eventually will be clarified. In principle, we aimed for an open tool without a strict order to complete it 
and one that would invite its users to reflect for a longer time on the listed items. Eventually, the completed canvas could serve as a conversation starter to discuss both their search process and proposed subject.

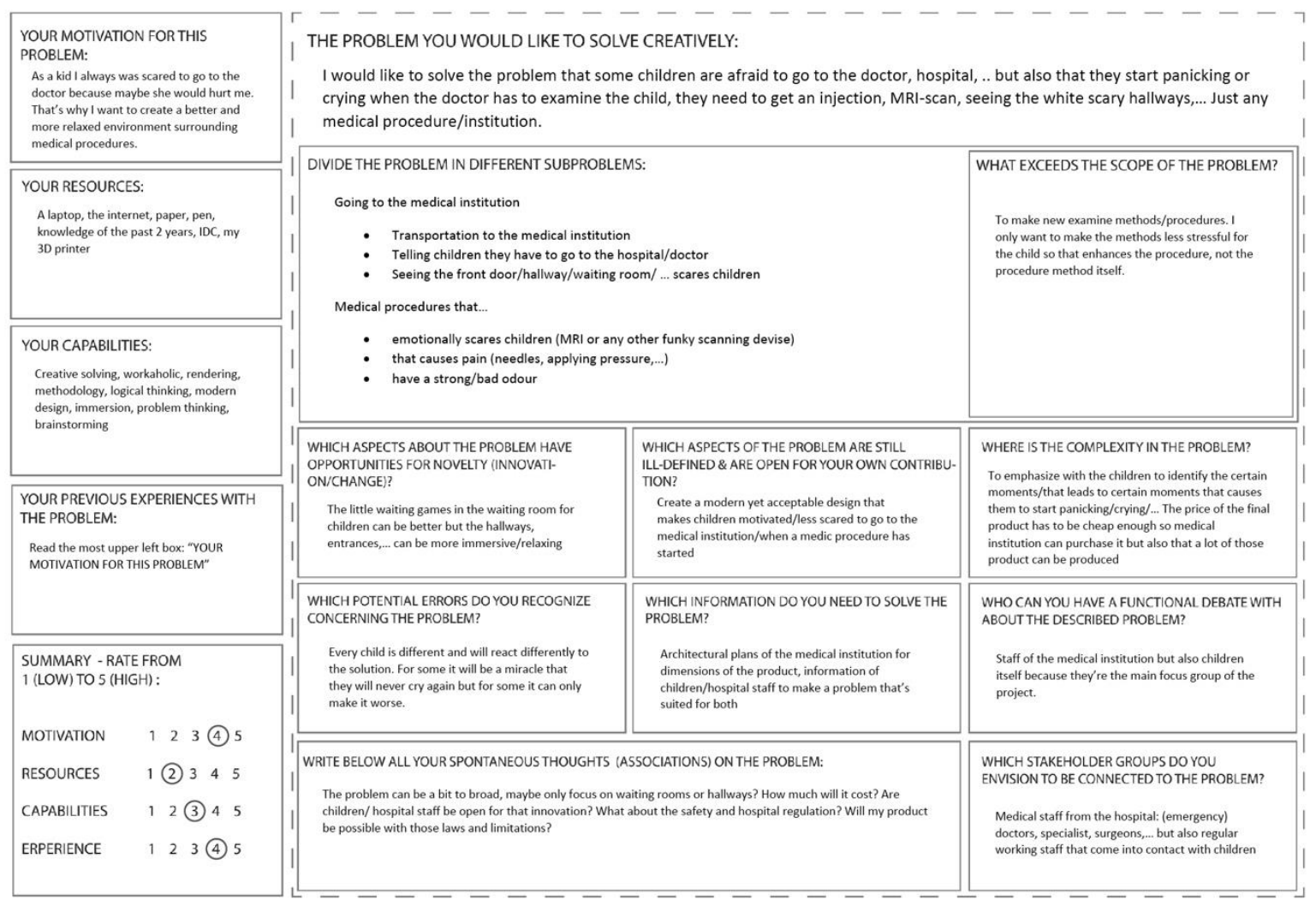

Figure 2. Tool completed at home (1 week), by one of the interviewed students

\subsection{Gathering feedback}

By means of screen and voice recordings of the students (capturing their thinking-aloud process), we got insights in how the brainstorm sessions (both with and without the tool) were proceeded. An online survey that was completed after the in-class brainstorm and repeated one week later, augmented our understanding in the students' reflections on both the tool and their quest for a thesis subject. Ultimately, we expanded our learnings by interviewing five students. Three out of these five scored above average on the final deliverable, while two underperformed. These scores were given by all three authors independently and based on a rubric. The interviews were semi-structured and based on an overview of the collected materials, i.e., deliverables and completed surveys by these five students. The outcome of the interviews has been processed under the next section of this paper.

\section{FINDINGS \& DISCUSSION}

An overall remark showed that the task given was not sufficiently clear for the students. Providing a checklist (with the most important expectations regarding master theses) at the beginning of this process, would give students some essential grip without asking them to complete a fixed canvas at that stage. Furthermore, our guidance could become gradually more structured during the process: at first posing some questions during the divergent subject exploration [17], but then a more converging version of the tool to select several subjects of interest and translate these into wicked problems. Just as suggested by the proposed benchmarks, the students should pass through several iterations, so they would gather sufficient information to make a substantiated choice between the various challenges that excite them. Some students seemed to struggle with the 'self' as a starting point. One student said, "I have the feeling that I did not do anything, besides writing about myself". Others took this opportunity for a related topic of interest and even balanced their own capabilities to a more general validation of the subject. For the intended purpose, to increase the students' internal motivation, we must formerly make students feel 
comfortable about this self-examination, and subsequently raise the awareness of modifying their interests in objectified challenges [16].

Furthermore, the user should be informed that potential causes or consequences not necessarily take place in the present [18]. Validating their initial ideas or own reasoning, by means of scientific literature or expert opinions, would not only strengthen the relevancy of the subject, but it would, additionally, lessen their lack of confidence. As long as student's thinking is predominated by their wish to succeed in their master's, no brainstorm or exercise will be totally spontaneous. Also, if more time is spent during the introductory brainstorms, students might, after summing up their ideas, start to evaluate them [17]. How can we delay critical thinking skills in this process?

Although students recognized the benefit of iterating the tool multiple times, most admitted they did not do so, neither had they the intention to do this in the future. This can be linked to the lay-out of the canvas, which unintendedly is perceived "closed" and "final". As a result, some students selected kind of randomly a topic to explore - "the last thought in my mind during the brainstorm"-, while others finished all steps -"with a broad subject that still leaves options open"-. And by doing so, did not make a manageable choice even at the end of the process. Perhaps, leaving a few input fields out of the canvas, and stimulating the students to only complete these during a next (validation) phase, could motivate an iterative use of the tool.

Compared to straight forwarded challenges, it is much harder to relate these complicated and ambiguous problems to previous solved questions. We try to avoid giving students a false sense of security, which would have been the case if we would already ask for solution-search directions [19]. The tool should find an equilibrium between confronting the users with the complexity of the spotted problem and proving some grip to keep the user believe in the achievability. We must challenge the users to switch off their analogy thinking when trying to fit a new topic into a former box. Surely, as long as one focuses exclusively on similarities, the envisaged possibilities remain limited [20].

Finally, asking for a list of subproblems might also be problematic when the users consider these as detached from each other and are planning to deal with them separately. On the contrary, addressing single parts of the problem-puzzle does not guarantee a successful solving of the underlying challenge, and might be contra productive [9]. An improvement of the tool should provide a larger input field where relations between the several subproblems can be drawn. The canvas should be able to show that conflicting requirements are possible and can be fruitful [5].

\begin{tabular}{|c|c|c|c|c|c|c|}
\hline \multicolumn{4}{|c|}{ In class } & \multicolumn{3}{|c|}{ At home } \\
\hline & $\begin{array}{c}\text { SUBJECT } \\
\text { EXPLORATION }\end{array}$ & & & $\begin{array}{c}\text { PROBLEM } \\
\text { IDENTIFICATION }\end{array}$ & $\begin{array}{l}\text { PROBLEM } \\
\text { VALIDATION }\end{array}$ & PROBLEM DEFINITION \\
\hline $\begin{array}{c}\text { Intro \& } \\
\text { examples of } \\
\text { master thesis }\end{array}$ & $\begin{array}{l}\text { Semi-guided } \\
\text { brainstorm on } \\
\text { master thesis } \\
\text { subjects inspired } \\
\text { by student's } \\
\text { interests }\end{array}$ & $\begin{array}{l}\text { Tool introduction: } \\
\text { - } \text { from subject to } \\
\text { problem } \\
\text { - } \text { from personal interest } \\
\text { to a generally } \\
\text { valuable problem }\end{array}$ & $\begin{array}{l}\text { Guided } \\
\text { brainstorm } \\
\text { (explore } \\
\text { the tool a } \\
\text { first time) }\end{array}$ & $\begin{array}{l}\text { Complete the tool three } \\
\text { times, to identify } \\
\text { three different } \\
\text { problems } \\
(3 \text { weeks })\end{array}$ & $\begin{array}{l}\text { Finalize the tool } \\
\text { based on } \\
\text { literature research } \\
\text { and/or expert } \\
\text { interview(s) }\end{array}$ & $\begin{array}{l}\text { Write a text about one } \\
\text { generally valuable problem } \\
\text { and the methodological approach } \\
\text { you consider to follow during } \\
\text { your master thesis } \\
\text { (6 weeks) }\end{array}$ \\
\hline
\end{tabular}

Figure 3. Proposal: adjusted master thesis search process

For future steps, we propose an enhanced version of the process in which the tool is implemented (Figure 3 ). We plan to test both this process and an adjusted canvas with next year undergraduates. By sharing our findings, we hope to inspire our peers to try out alternative ways to let students experiment with problem-finding, before they start thinking on solving these wicked issues.

\section{REFERENCES}

[1] Mumford M. D. and Gustafson S. B. Creative thought: Cognition and problem solving in a dynamic system. In Creativity research handbook, volume 2, 2007 (Cresskill, NJ: Hampton).

[2] Wakefield J. F. Towards creativity: Problem finding in a divergent-thinking exercise. Child Study Journal, 1985, 15(4), pp. 265-270.

[3] Arreola N. J. and Reiter-Palmon R. The effect of problem construction creativity on solution creativity across multiple everyday problems. Psychology of Aesthetics, Creativity, and the Arts, 2016, 10, pp. 287-295.

[4] Abdulla A. M., Paek S. H., Cramond B., and Runco M. A. Problem finding and creativity: A meta-analytic review. Psychology of Aesthetics, Creativity, and the Arts, 2018, 14(1), 3. 
[5] Lee J. W., Daly S. R., Huang-Saad A., Rodriguez G., and Seifert C. M. Cognitive strategies in solution mapping: How engineering designers identify problems for technological solutions. Design Studies, 2020, 71, 100967.

[6] Becattini N., Borgianni Y., Cascini G. and Rotini F. Coaching the cognitive processes of inventive problem solving with a computer. In Design Creativity, 2010, pp. 289-296 (Springer, London).

[7] Rittel H. W. J. and Webber M. M. Dilemmas in a general theory of planning. Policy Sciences, 1973, 4(2), pp. 155-169.

[8] Wang J., Veugelers R., and Stephan P. Bias against novelty in science: A cautionary tale for users of bibliometric indicators. Research Policy, 2017, 46(8), pp. 1416-1436.

[9] Liu H. Y. and Maas M. M. 'Solving for X?' Towards a problem-finding framework to ground long-term governance strategies for artificial intelligence. Futures, 2021, 126, 102672.

[10] Runco M. A. (Ed.). Creativity research handbook, volume 2, 2007 (Cresskill, NJ: Hampton).

[11] Dorst K. and Cross N. Creativity in the design process: Co-evolution of problem-solution. Design Studies, 2001, 22(5), pp. 425-437.

[12] Tschimmel K. Evolution $6^{2}$ Toolkit: An E-handbook for Practical Design Thinking for Innovation, 2018, Mindshake.

[13] De Marez L. User Innovation Toolbox, 2018 (Pelckmans, Kalmthout).

[14] Rubenstein L. D., Callan G. L., Neumeiste K. S. and Ridgley L. M. Finding the problem: How students approach problem identification. Thinking Skills and Creativity, 2020, 35, 100635.

[15] Dorst K. Design Problems and Design Paradoxes. Design issues, 2006, 22, pp. 4-17.

[16] Vansteenkiste M., Lens W. and Deci E. L. Intrinsic versus extrinsic goal contents in selfdetermination theory: Another look at the quality of academic motivation. Educational Psychologist, 2006, 41(1), pp. 19-31.

[17] Olander E. Teaching creativity by change of mind-set: from goal oriented to open and curious. In DS 93: Proceedings of the 20th International Conference on Engineering and Product Design Education, E\&PDE 2018, London, September 2018, pp. 248-253.

[18] MacKenzie M. K. There is no such thing as a short-term issue. Futures, 2021, 125, 102652.

[19] Chomsky N. Problems and mysteries in the study of human language. In Language in focus: Foundations, methods and systems, pp. 281-357, 1976 (Springer, Dordrecht).

[20] Mandel G. N. Legal evolution in response to technological change. The Oxford handbook of law, regulation and technology, 2017. 